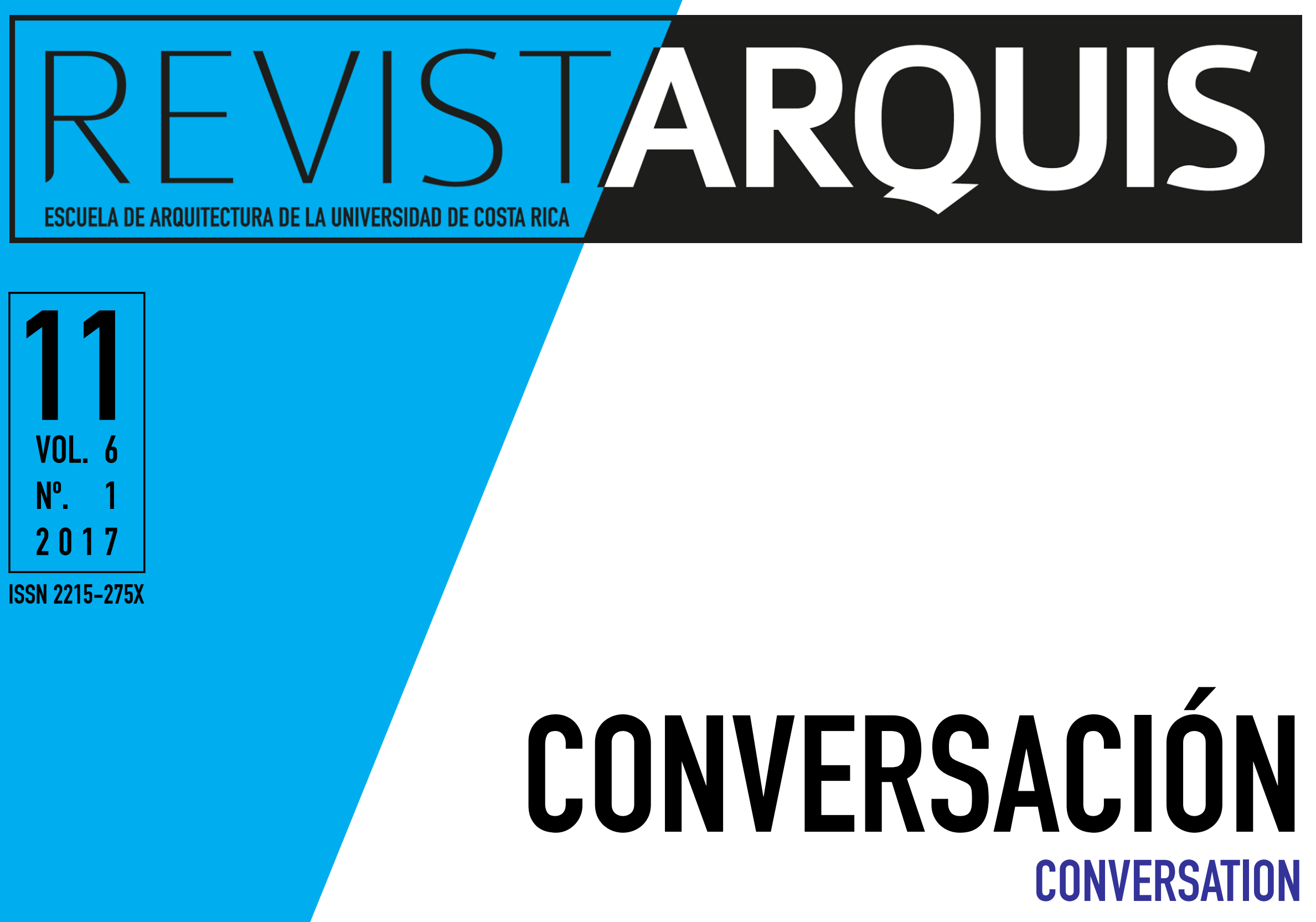

10_ Entrevista a Arquitecta Marian Pérez Jorge Grané del Castillo | 90-92 


\title{
Entrevista a arquitecta Marian Pérez
}

\author{
Jorge Grané del Castillo
}

\begin{abstract}
Resumen
El postulado de los fundadores de la Escuela de Arquitectura de la UCR era "aprender a aprender". Los estudiantes estaban obligados a asimilar esta nueva forma de estudiar. Marian Pérez, egresada en 1981, aprendió que el estudio de la Arquitectura permite descubrir caminos alternos para el desarrollo personal. En su paso por la Escuela encontró un fuerte apoyo de los profesores que la ayudaron a resolver sus incertidumbres. Después de graduarse, sus diversos trabajos se enfocaron hacia el tema de la planificación y la vivienda. Actualmente es viceministra de Vivienda.
\end{abstract}

Palabras clave: aprender; Escuela de Arquitectura; incertidumbres; otros caminos; planificación y vivienda.

\section{Abstract}

\section{Marian Pérez Gutiérrez}

Egresada de la Escuela de Arquitectura de la Universidad de Costa Rica; tiene un diplomado avanzado en planificación y construcción de vivienda del Institute for Housing StudiesRotterdam, Holanda. Fue profesora investigadora de FLACSO Costa Rica; ocupó el cargo de docente universitaria en las escuelas de Arquitectura de la Universidad de Costa Rica, Universidad Latina y Universidad Veritas; trabajó de investigadora de CIVCO del Tecnológico de Costa Rica (TEC); tenía la dirección de Vivienda antes de ocupar el cargo actual de Viceministra de Vivienda y Asentamientos Humanos de Costa Rica. marianperezgut@gmail.com

\section{Jorge Grané del Castillo}

Licenciatura en Periodismo, UACA, Costa Rica,

1991. Licenciatura en Arquitectura, Argentina, 1967 Docente, Escuela de Arquitectura de la Universidad de Costa Rica (UCR)

jorgegrane@gmail.com
The postulate of the founders of the School of Architecture of the UCR was "learning to learn". The students were obliged to assimilate this new way of studying. Mariam Pérez, who graduated in 1981, learned that the study of architecture allows the discovery of alternative paths for personal development. In her passage through the School she found strong support from the teachers who helped her solve her uncertainties. After graduating, her various works focused on the subject of planning and housing. She is currently Deputy Minister of Housing.

Keywords: learning; School of Architecture; uncertainties; new ways; planning and housing. 
odemos conocer, por medio de entrevistas y declaraciones, los intentos y el esfuerzo de quienes llevaron a cabo la lucha por crear nuestra Escuela de Arquitectura. Pero poco se ha hablado de los estudiantes que acompañaron a estos visionarios en la aventura, y que tuvieron con los profesores una curiosa relación de maestro-alumno donde no había barreras que los separaban.

La innovadora propuesta de "aprender a aprender" debía ser asimilada por los estudiantes que estaban acostumbrados a la rígida enseñanza del maestro que actuaba programado por el programa. Nadie podía salirse de las gavetas que tenían por etiqueta el nombre de cada materia indicada en el programa de estudios. La propuesta de la Escuela de Arquitectura de la Universidad de Costa Rica (UCR) era otra.

Las ideas de los artífices de la Escuela de Arquitectura, Rafael (Felo) García, Jorge Bertheau y Edgar Brenes eran innovadoras, revolucionarias y provocadoras.

Los primeros estudiantes de la Escuela debían enfrentar un juego cuyas reglas se iban consolidando con el quehacer diario, a prueba y error. Esto desconcertaba a algunos, sorprendía a todos y entusiasmaba a muchos.

Cada cual guarda su pasado consigo. Cada estudiante ha vivido su historia personal en su paso por la Escuela de Arquitectura, y es importante conocer sus experiencias en el proceso de formación que sufrió y disfrutó en esos años de estudio.

Por eso escogimos a Marian Pérez, egresada en 1981; para que nos contara sus experiencias, buenas y malas, como estudiante de Arquitectura, en aquellos años en que se iniciaba nuestra Escuela.

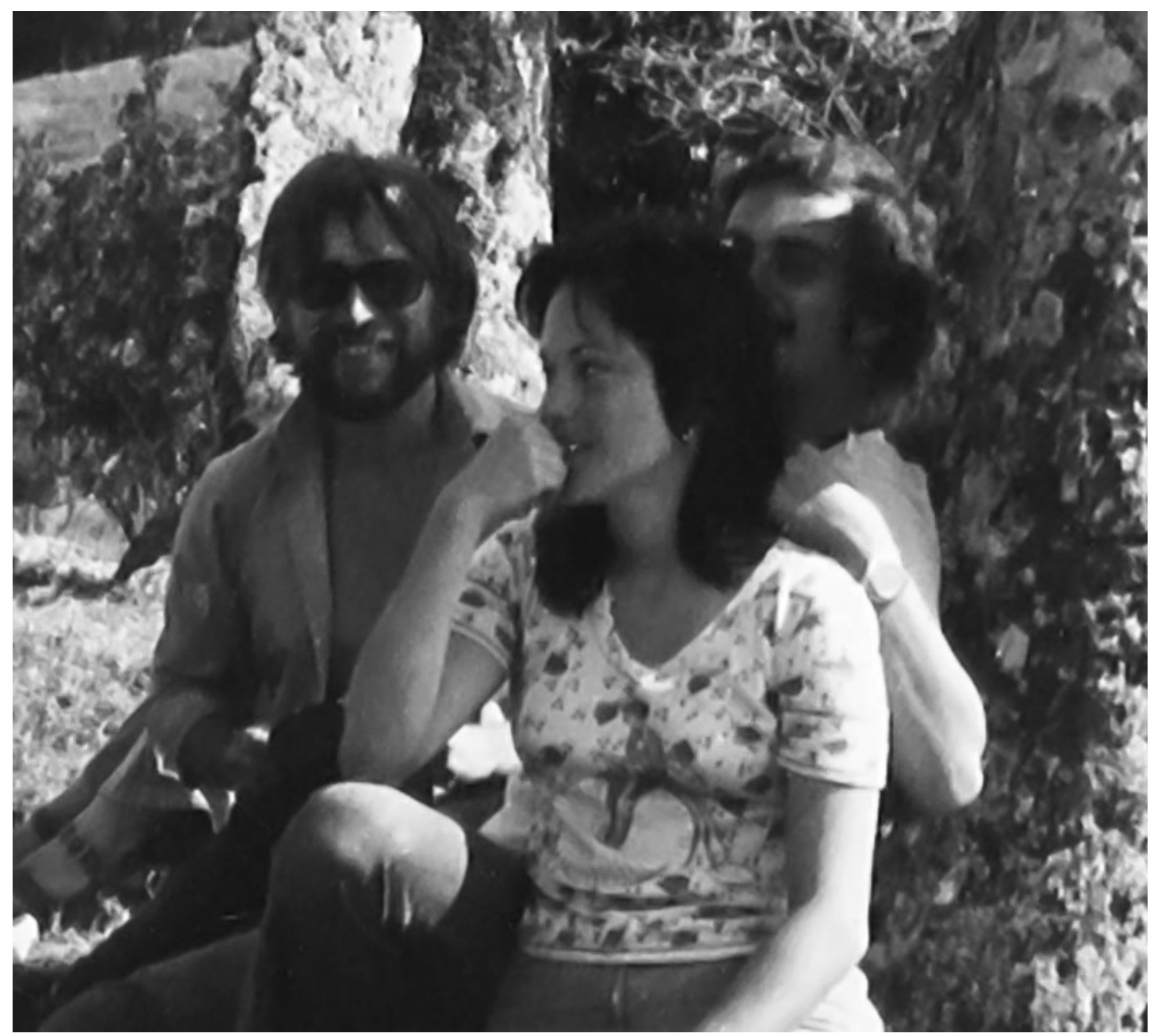

Lo primero que hay que destacar es que Marian no estaba enormemente entusiasmada por seguir esta carrera sino que era una opción universitaria que le llamaba la atención; más que cualquier otra. Es importante recalcar esto, porque es la situación en la que se encuentran muchos de nuestros estudiantes que, una vez graduados, escogen una actividad afin a la Arquitectura como salida laboral. Marian encontró en la Escuela, como muchos otros, una guía que le hizo descubrir los múltiples caminos de la Arquitectura.

Su padre, como funcionario internacional, debió asentarse, con su familia, en varios países y así fue como Marian empezó, a los 17 años, a cursar Arquitectura en la revuelta, por entonces, Universidad Javeriana de Colombia. Más tarde tuvo que trasladarse a la Universidad Federal de Río de Janeiro donde estuvo tres años, suficiente tiempo para cuestionarse su vocación, su identidad y sus ganas de volver a su país. 
